\title{
Novel Green Biosynthesis of 5-Fluorouracil Chromium Nanoparticles Using Harpullia pendula Extract for Treatment of Colorectal Cancer
}

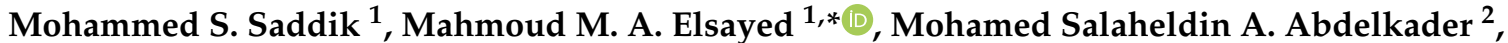 \\ Mohamed A. El-Mokhtar ${ }^{3}{ }^{\mathbb{D}}$, Jelan A. Abdel-Aleem ${ }^{4}$, Ahmed M. Abu-Dief ${ }^{5,6} \mathbb{D}^{\mathbb{D}}$, Mostafa F. Al-Hakkani ${ }^{7}$ (D), \\ Hatem S. Farghaly ${ }^{8}$ and Heba A. Abou-Taleb ${ }^{9}$ (D)
}

Citation: Saddik, M.S.; Elsayed, M.M.A.; Abdelkader, M.S.A.; El-Mokhtar, M.A.; Abdel-Aleem, J.A.; Abu-Dief, A.M.; Al-Hakkani, M.F.; Farghaly, H.S.; Abou-Taleb, H.A. Novel Green Biosynthesis of 5-Fluorouracil Chromium Nanoparticles Using Harpullia pendula Extract for Treatment of Colorectal Cancer. Pharmaceutics 2021, 13, 226. https://doi.org/10.3390/pharmaceutics 13020226

Academic Editor: Crispin R. Dass Received: 5 December 2020

Accepted: 2 February 2021

Published: 6 February 2021

Publisher's Note: MDPI stays neutral with regard to jurisdictional claims in published maps and institutional affiliations.

Copyright: (c) 2021 by the authors. Licensee MDPI, Basel, Switzerland. This article is an open access article distributed under the terms and conditions of the Creative Commons Attribution (CC BY) license (https:/ / creativecommons.org/licenses/by/ $4.0 /)$.
1 Department of Pharmaceutics and Clinical Pharmacy, Faculty of Pharmacy, Sohag University, P.O. Box 82524, Sohag 82524, Egypt; mohammed.sherif@pharm.sohag.edu.eg

2 Department of Pharmacognosy, Faculty of Pharmacy, Sohag University, Sohag 82524, Egypt; m.salaheldin@pharm.sohag.edu.eg

3 Department of Medical Microbiology and Immunology, Faculty of Medicine, Assiut University, Assiut 71516, Egypt; elmokhtarma@aun.edu.eg

4 Department of Industrial Pharmacy, Faculty of Pharmacy, Assiut University, Assiut 71516, Egypt; Jelan.abdelrazik@pharm.aun.edu.eg

5 Chemistry Department, College of Science, Taibah University, Madinah 42353, Saudi Arabia; amamohammed@taibahu.edu.sa

6 Chemistry Department, Faculty of Science, Sohag University, Sohag 82524, Egypt

7 Department of Chemistry, Faculty of Science, New Valley University, Al-Kharja 72511, Egypt; mostafa.f@scinv.au.edu.eg

8 Department of Biochemistry, Faculty of Pharmacy, Nahda University (NUB), Beni-Sueif 62511, Egypt; hatemsayed@rocketmail.com

9 Department of Pharmaceutics and Industrial Pharmacy, Faculty of Pharmacy, Nahda University (NUB), Beni-Suef 62511, Egypt; heba.elsayed@nub.edu.eg

* Correspondence: mahmoudalmenshawy@pharm.sohag.edu.eg; Tel.: +20-1226770470

Abstract: Colorectal cancer (CRC) is the third highest major cause of morbidity and mortality worldwide. Hence, many strategies and approaches have been widely developed for cancer treatment. This work prepared and evaluated the antitumor activity of 5-Fluorouracil (5-Fu) loaded chromium nanoparticles (5-FuCrNPs). The green biosynthesis approach using Harpullia (H) pendula aqueous extract was used for CrNPs preparation, which was further loaded with 5-Fu. The prepared NPs were characterized for morphology using scanning and transmission electron microscopes (SEM and TEM). The results revealed the formation of uniform, mono-dispersive, and highly stable CrNPs with a mean size of $23 \mathrm{~nm}$. Encapsulation of 5-Fu over CrNPs, with a higher drug loading efficiency, was successful with a mean size of $29 \mathrm{~nm}$ being produced. In addition, Fourier transform infrared (FTIR) and X-ray diffraction pattern (XRD) were also used for the investigation. The drug 5-Fu was adsorbed on the surface of biosynthesized CrNPs in order to overcome its clinical resistance and increase its activity against CRC cells. Box-Behnken Design (BBD) and response surface methodology (RSM) were used to characterize and optimize the formulation factors (5-Fu concentration, CrNP weight, and temperature). Furthermore, the antitumor activity of the prepared 5-FuCrNPs was tested against CRC cells (CACO-2). This in vitro antitumor study demonstrated that 5-Fu-loaded CrNPs markedly decreased the IC50 of 5-Fu and exerted more cytotoxicity at nearly all concentrations than 5-Fu alone. In conclusion, 5-FuCrNPs is a promising drug delivery system for the effective treatment of CRC.

Keywords: chromium nanoparticles; 5-Flourouracil; colorectal cancer; green biosynthesis

\section{Introduction}

Colorectal cancer (CRC) is the third highest major cause of morbidity and mortality worldwide [1]. Many strategies have been developed for cancer treatment, including 
surgery, chemotherapy, and radiation [2-4]. Despite advances in treatment strategies, resistance to chemotherapy represents a challenge in the management of the incurable metastatic disease [5].

The drug 5-Fluorouracil (5-Fu) is a well-known chemotherapeutic agent, used as a first-line treatment for CRC $[6,7]$. The drug represses DNA synthesis by hindering thymidylate synthetase [8]. However, the acquired drug resistance, short half-life of 10-20 min, and harmful side effects on the bone marrow and gastrointestinal tract (GIT), remain among the limitations of its clinical use $[9,10]$. Quite recently, considerable attention has been paid to using 5-Fu-based mix regimens and 5-Fu pro-drugs to conquer the clinical opposition and increase its anti-tumor activity [6].

In the last two decades, nanotechnology has gained great attention from medical, pharmaceutical, and chemical scientists because of its tremendously valuable uses in different fields. Nanoparticles (NPs) are popular drug delivery systems due to their controllable size, surface properties, and drug release dynamics [11-16].

Chromium $(\mathrm{Cr})$ is a basic supplement associated with the guideline of carbohydrate and lipid metabolism [17]. It has been reported that the administration of $\mathrm{Cr}$ is associated with weight loss and diminishing body fat [18]. In addition, $\mathrm{Cr}$, a naturally substantial metal, is widely used in electroplating, pigmenting, wood safeguarding, cowhide tanning, steel fabricating, material coloring, and paper and mash enterprises [19]. Alternatively, the drug has also been included or adsorbed on the outside of transporters. Nanoparticles have propelled research in drug delivery by facilitating changes in the dispersion of medications in the body and the delivery rate, expanding drug bioavailability and the porosity of the membrane [20-23]. However, studies on CrNPs are still lacking [24].

Green preparations of nanoparticles using plant extracts as capping and reducing agents are gaining popularity in the field of nanotechnology $[25,26]$. The reasons behind the use of this methodology include the fact it is centered around the use of environmentally friendly, financially savvy, and biocompatible lessening specialists for the combination of nanoparticles [27,28]. Members of the genus Harpullia are known to be rich sources of saponins, triterpenes, tannins, flavonoids, and sterols [29-34].

In this study, we used the aqueous extract of $H$. pendula in the green biosynthesis of CrNPs, that were then loaded with 5-Fu to yield improvements in its anti-cancer activity. As far as we know, this is the first study that has reported on the formulation of 5-Fu-loaded CrNPs for possible use in the treatment of CRC. The prepared NPs were characterized for size, morphology, FTIR, and XRD. In addition, the in vitro anti-tumor activity of 5-FuCrNPs against a colorectal cell line (CACO-2) was investigated.

\section{Material and Methods}

\subsection{Materials}

Chromium chloride $\left(\mathrm{CrCl}_{3} \cdot 6 \mathrm{H}_{2} \mathrm{O}\right)$ and 5-fluorouracil (5- $\left.\mathrm{Fu}\right)$ were purchased from Sigma-Aldrich (St. Louis, MO, USA).

The leaves of $H$. pendula were collected from the field of elaborate plants Faculty of Agriculture, Assiut University, Assiut, Egypt. All other solvents and reagents used in the study were of analytical grade and used as received.

\subsection{Methods}

\subsubsection{Plant Material and Extract Preparation}

The air-dried powdered leaves of H. pendula $(100 \mathrm{~g})$ were mixed with $250 \mathrm{~mL}$ distilled water, and then the mixture was heated and boiled for $20 \mathrm{~min}$ to obtain the aqueous extracts. After cooling, the mixture was filtered using Whatman No. 1 filter paper and stored in the refrigerator until further use. 


\subsubsection{Biosynthesis of Chromium Nanoparticles (CrNPs)}

A total amount of $0.1 \mathrm{M}$ of $\mathrm{CrCl}_{3} \cdot 6 \mathrm{H}_{2} \mathrm{O}$ was prepared by dissolving $26.6 \mathrm{~g}$ of $\mathrm{CrCl}_{3} \cdot 6 \mathrm{H}_{2} \mathrm{O}$ in $1 \mathrm{~L}$ of distilled water in a beaker with the aid of sonication. This was then kept until use. A total of $10 \mathrm{~mL}$ aqueous solution of $H$. pendula extract was mixed with $10 \mathrm{~mL}$ solution of $\mathrm{CrCl}_{3} \cdot 6 \mathrm{H}_{2} \mathrm{O}$ at $35^{\circ} \mathrm{C}$. The mixture was stirred vigorously suing a magnetic stirrer for two hours then left in the dark for $24 \mathrm{~h}$ until the synthesis of CrNPs was complete. Later, the prepared chromium NPs were separated by centrifugation at 10,000 rpm for $10 \mathrm{~min}$ (Refrigerated Centrifuge. Model H3-20KR, Hunan Kecheng, Changsha, China). The supernatant was removed, and the residue was washed three times with deionized water. Finally, the precipitated CrNPs were dried in an oven for $1 \mathrm{~h}$ at $100^{\circ} \mathrm{C}$.

\subsubsection{Preparation of 5-Fu Loaded Chromium Nanoparticles (5-FuCrNPs)}

Fifteen formulae of 5-FuCrNPs were prepared using Box-Behnken Design (BBD) $[35,36]$. Three independent variables were chosen: 5 -Fu concentration $(0.25,0.5$ and $0.75 \%)$, the weight of CrNPs (250, 500 and $750 \mathrm{mg})$, and reflux temperature in the water bath shaker $\left(20 \pm 1{ }^{\circ} \mathrm{C}\right.$, $25 \pm 1{ }^{\circ} \mathrm{C}$, and $30 \pm 1{ }^{\circ} \mathrm{C}$ ). CrNPs were added to previously prepared $200 \mathrm{~mL}$ aqueous solutions of different concentrations of 5-Fuin volumetric flasks $(250 \mathrm{~mL})$. They were then placed in a thermostatically controlled water bath shaker that was operated at different temperature degrees and $500 \mathrm{rpm}$ for $24 \mathrm{~h}$. Finally, the prepared 5-FuCrNPs were separated from the solution by ultrafiltration using a $50 \mathrm{kDa}$ pore size filter [37].

\subsubsection{Characterization of the Prepared NPs.}

Both CrNPs and 5-FuCrNPs were characterized using the following measurements.

X-ray Powder Diffraction (XRD)

XRD measurement was performed using a Philips X-ray diffractometer (PW 1710, Anode material $\mathrm{Cu}$, at a voltage of $40 \mathrm{kV}$, current of $30 \mathrm{~mA}$, Wavelength $1.541838 \AA(\mathrm{Cu})$, Optics: Automatic divergence slit, Beta filtering using graphite, monochromator) for CrNPs.

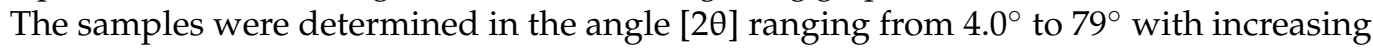
step by $0.06^{\circ}$.

Fourier Transform Infrared Spectroscopy (FTIR)

Infrared spectra of CrNPs and 5-FuCrNPs were examined using (Nicolet iS10 FTIR Spectrometer, Thermo Fisher Scientific, Waltham, MA, USA). Each sample was prepared, by mixing with $200 \mathrm{mg}$ of $\mathrm{KBr}$, followed by compressing under high pressure.

Scanning Electron Microscopy (SEM)

Each sample of solid CrNPs and 5-FuCrNPs was prepared by adhesion on doubleadhesive carbon tape, which was coated with a gold thin film with a diameter of 150 to $200 \AA$. They were then scanned by a scanning electron microscope (JEOL model, Tokyo, Japan: JSM 5400LV) to investigate the structure and morphology of the sample.

Transmission Electron Microscopy (TEM)

Each sample of solid CrNPs and 5-FuCrNPs were prepared by dispersion in ethanol as a solvent before precipitating on the grid, and coating with a thin film of carbon. Finally, the samples were left to dry before being scanned by the transmission electron microscope (JEOL model: JEM-100 CXII, Tokyo, Japan). The particle size distribution of the prepared NPs was evaluated using image J Launcher, Tokyo, Japan, broken-symmetry software, version (1.4.3.6.7). 
Determination of Drug Loading Efficiency Percentage (LE\%)

The concentration of 5-Fu loaded on chromium NPs was spectrophotometrically determined by direct determination of unbound 5-Fu in the filtrate at $\lambda_{\max } 265 \mathrm{~nm}$.

The amount of 5-Fu adsorbed by chromium nanoparticles $\mathrm{q}_{\mathrm{e}}(\mathrm{mg} / \mathrm{g})$ was calculated from the following Equation (1) [38]:

$$
\mathrm{q}_{\mathrm{e}}=\left(\mathrm{C}_{0}-\mathrm{C}_{\mathrm{e}}\right) \mathrm{V} / \mathrm{m}
$$

where $\mathrm{C}_{0}$ and $\mathrm{C}_{\mathrm{e}}$ are the initial and equilibrium concentrations of $5-\mathrm{Fu}$. V is the volume of the $5-\mathrm{Fu}(\mathrm{mL})$ and $\mathrm{m}$ is the $\mathrm{Cr}$ nanoparticles mass in $\mathrm{mg}$.

The loading efficiency percentage ( $\mathrm{LE} \%$ ) of 5-Fu adsorption was determined relative to the original drug concentration added, according to the following Equation (2):

$$
\text { Loading Efficiency Percent }(\mathrm{LE} \%)=\left[\left(\mathrm{C}_{0}-\mathrm{C}_{\mathrm{e}}\right) / \mathrm{C}_{0}\right] \times 100
$$

\subsubsection{In Vitro Drug Release Study}

In vitro release of 5 -Fu from the formulated $\mathrm{CrNPs}$ was performed at $37^{\circ} \mathrm{C}$, predicted using a dissolution medium $\mathrm{pH}$ shift method with a paddle type dissolution test apparatus, SR II, 6 flasks (Hanson Research Co., Chatsworth, CA, USA) adjusted at 50 rpm [28,39]. In brief, $500 \mathrm{~mL}$ of simulated gastric fluid ( $\mathrm{pH} 1.2)$ was used as the release medium for $1 \mathrm{~h}$, followed by the addition of $5 \mathrm{~mL}$ of $7 \mathrm{M} \mathrm{KH}_{2} \mathrm{PO}_{4}$ containing $16.75 \%(w / v) \mathrm{NaOH}$ in order to shift the $\mathrm{pH}$ to 7.4. The experiment then proceeded for an additional $2 \mathrm{~h}$. Throughout the full experimental timeframe, a $3 \mathrm{~mL}$ aliquot was aspirated and filtered at every $30 \mathrm{~min}$ intervals to measure the absorbance at the foreordained $\lambda_{\max }$ of each media against a relating blank.

Experimental Design (BBD)

A Box-Behnken experimental design (BBD) was utilized to investigate and optimize the formulation parameters of 5-FuCrNPs preparation for maximum LE\% and fast drug delivery after 1 and $3 \mathrm{~h}[40,41]$. This design was used as it requires fewer treatment combinations in cases involving more than two dependent variables than are involved with other designs [42,43]. The BBD is also ratable and contains statistical "missing corners" which may be useful when the experimenter is trying to avoid combined factor extremes. This property prevents the potential loss of data in such cases [44]. A 3 factor 3 levels design was employed to design 5-FuCrNPs. The three independent formulation variables analyzed during the study were 5-Fu Concentration $\left(X_{1}\right), \operatorname{CrNP}$ weight $\left(X_{2}\right)$, and temperature $\left(\mathrm{X}_{3}\right)$. The selected factors with the actual and coded levels, as per the design, are represented in Table 1. According to this design, 15 formulae of 5-FuCrNPs were prepared. Three levels of $5-\mathrm{Fu}$ concentration were used, $0.25,0.5$, and $0.75 \%$, denoted by the values $-1,0$, and +1 , respectively, in the above design. The different CrNP weights used were 250,500 , and $750 \mathrm{mg}$, also denoted the values $-1,0$, and +1 , respectively. Lastly, the reflux temperature was chosen to be $20 \pm 1^{\circ} \mathrm{C}, 25 \pm 1^{\circ} \mathrm{C}$, and $30 \pm 1^{\circ} \mathrm{C}$ denoted $-1,0$, and +1 values, respectively. The dependent variables to be tested for the prepared 5-FuCrNPs were chosen to be the loading efficiency $\left(Y_{1}\right)$, release at the end of $1 \mathrm{~h}\left(\mathrm{Y}_{2}\right)$, and release at the end of $3 \mathrm{~h}\left(\mathrm{Y}_{3}\right)$. 
Table 1. Observed values of responses for 5-fluorouracil chromium nanoparticles (5-FuCrNPs).

\begin{tabular}{|c|c|c|c|c|c|c|}
\hline \multirow[b]{2}{*}{ Formula No. } & \multicolumn{3}{|c|}{ The Variable Level in a Coded Form } & \multirow{2}{*}{$\begin{array}{c}\text { LE\% } \\
Y_{1} \\
\text { LE \% }\end{array}$} & \multicolumn{2}{|c|}{ Cumulative Percentage Released } \\
\hline & $\begin{array}{c}\mathrm{X}_{1} \\
\text { 5-Fu Conc. }\end{array}$ & $\begin{array}{c}X_{2} \\
\text { CrNP Weight }\end{array}$ & $\begin{array}{c}X_{3} \\
\text { Temperature }\end{array}$ & & $\begin{array}{c}\mathrm{Y}_{2} \\
\operatorname{Rel} 1 \mathrm{~h}\end{array}$ & $\begin{array}{c}\mathrm{Y}_{3} \\
\text { Rel 3 h }\end{array}$ \\
\hline N1 & -1 & -1 & 0 & $55.87 \pm 2.03$ & $14.88 \pm 1.88$ & $62.15 \pm 1.96$ \\
\hline N2 & 0 & -1 & -1 & $75.64 \pm 3.98$ & $18.26 \pm 1.93$ & $81.77 \pm 1.11$ \\
\hline N3 & 0 & -1 & 1 & $67.31 \pm 2.23$ & $24.12 \pm 1.77$ & $90.77 \pm 1.72$ \\
\hline N4 & 1 & -1 & 0 & $74.32 \pm 2.08$ & $21.90 \pm 1.65$ & $79.42 \pm 1.33$ \\
\hline N5 & -1 & 0 & -1 & $80.25 \pm 2.21$ & $11.89 \pm 1.98$ & $76.09 \pm 1.94$ \\
\hline N6 & -1 & 0 & 1 & $67.76 \pm 3.05$ & $9.83 \pm 1.34$ & $68.13 \pm 1.56$ \\
\hline N7 & 0 & 0 & 0 & $74.13 \pm 2.06$ & $18.14 \pm 1.65$ & $87.11 \pm 1.65$ \\
\hline N8 & 0 & 0 & 0 & $83.23 \pm 4.12$ & $14.24 \pm 1.74$ & $84.51 \pm 1.44$ \\
\hline N9 & 0 & 0 & 0 & $80.99 \pm 3.11$ & $14.02 \pm 1.83$ & $82.93 \pm 1.76$ \\
\hline N10 & 1 & 0 & -1 & $92.11 \pm 3.23$ & $18.33 \pm 1.43$ & $91.23 \pm 1.34$ \\
\hline N11 & 1 & 0 & 1 & $81.91 \pm 3.87$ & $16.36 \pm 1.87$ & $92.73 \pm 1.33$ \\
\hline N12 & -1 & 1 & 0 & $74.33 \pm 2.99$ & $9.88 \pm 1.96$ & $71.45 \pm 1.93$ \\
\hline N13 & 0 & 1 & -1 & $85.89 \pm 2.01$ & $16.02 \pm 1.54$ & $80.69 \pm 1.25$ \\
\hline N14 & 0 & 1 & 1 & $76.81 \pm 3.43$ & $18.61 \pm 1.66$ & $69.93 \pm 1.54$ \\
\hline N15 & 1 & 1 & 0 & $87.54 \pm 2.02$ & $15.92 \pm 1.99$ & $74.18 \pm 1.63$ \\
\hline
\end{tabular}

\subsubsection{Effect on Cell Proliferation}

The effect of 5-Fu, CrNPs, and 5-FuCrNPs on the viability of the CACO-2 cell line (Colorectal adenocarcinoma cell line, kindly supplied from VACSERA tissue culture lab, Obour City, Cairo, Egypt) was investigated using the MTT cell proliferation assay (Cell Titer $96{ }^{\circledR}$ Non-Radioactive Cell Proliferation Assay, Promega, Dane County, WI, USA) according to the manufacturer's instructions. In brief, 5000 cells were plated in wells of $96-$ well plate in triplicates and incubated at $37{ }^{\circ} \mathrm{C}$ in a $5 \% \mathrm{CO}_{2}$ incubator (Thermo Fisher Scientific, Waltham, MA, USA) for $24 \mathrm{~h}$. On the next day, different concentrations of 5-Fu, CrNPs, and $5-\mathrm{FuCrNPs}$ were added to the cells and treated cells were incubated for $24 \mathrm{~h}$. Control cells were treated with PBS. After incubation, the MTT reagent was added to the cells and incubated for $4 \mathrm{~h}$ in the dark, followed by the addition of the stop solution to dissolve the formed crystals. The absorbance of the solution was measured at wavelengths of 570 and $630 \mathrm{~nm}$ (reference filter). Cell viability was expressed as the mean percentage of viability and was calculated by dividing the optical density of the treated sample/optical density of the control samples. The IC50 (the concentration of the sample that caused a 50\% inhibition of cell viability) was determined from the nonlinear regression curve obtained by plotting the log concentration of the inhibitor vs. cell viability as a percentage. Each concentration of the inhibitor was tested in triplicate. Data are presented as the average IC50 for the tested inhibitory material. Growth curves and regression analysis were performed using GraphPad Prism 8.4 (GraphPad Software, San Diego, CA, USA).

In addition, the ability of 5-Fu, and 5-FuCrNPs to induce apoptosis of the CACO-2 cells was analyzed by flowcytometry using annexin $\mathrm{V}$ and a propidium iodide staining kit (Thermo Fisher Scientific, Suwanee, GA, USA). Cells were acquired on FACSCalibur ${ }^{\mathrm{TM}}$ flow cytometer (BD Biosciences, San Jose, CA, USA) and data were analyzed by FlowJo software 8.7 (Treestar, Ashland, OR, USA).

\section{Results and Discussion}

In the current study, CrNPs were successfully produced using an eco-friendly green synthesis approach (Figure 1) [15]. The biosynthesis of CrNPs was carried out using 
H. pendula aqueous extract as the reducing and capping agent. Additionally, the H. pendula plant has been reported to be a rich source of phenolics and flavonoids, with total contents of $255.5 \pm 7.18 \mathrm{mg}$ gallic acid equivalents/g extract, and $111.6 \pm 3.2 \mathrm{mg}$ quercetin equivalents/g extract, respectively [33]. Different flavonoids and polyphenolic compounds have previously been isolated and characterized from the $H$. pendula plant, including rutin, vitexin, isovitexin, orientin, quercetin, and kaempferol quercetin-3-O- $\beta$-Dglucoside, kaempferol-3-O- $\beta$-D-glucoside, kaempferol-3-O- $\beta$-D-glucopyranosyl- $(1 \rightarrow 2)-\alpha-\mathrm{L}$, rhamnopyranoside, kaempferol-3-O- $\beta$-D-glucopyranosyl- $(1 \rightarrow 4)-\alpha$-L-rhamnopyranoside, kaempferol-3-O- $\beta$-D-apiofuranosyl-( $1 \rightarrow 2)-\beta$-D-glucopyranoside, and kaempferol 3-O$\left(6^{\prime \prime}\right.$ galloyl) apiofuranosyl $\left(1^{\prime \prime \prime} \rightarrow 2^{\prime \prime}\right)-\beta$-galactopyranoside [31,33]. Additionally, members of this family have been widely studied for their antioxidant, anti-inflammatory, insecticidal, and anti-diabetic properties [45-48].

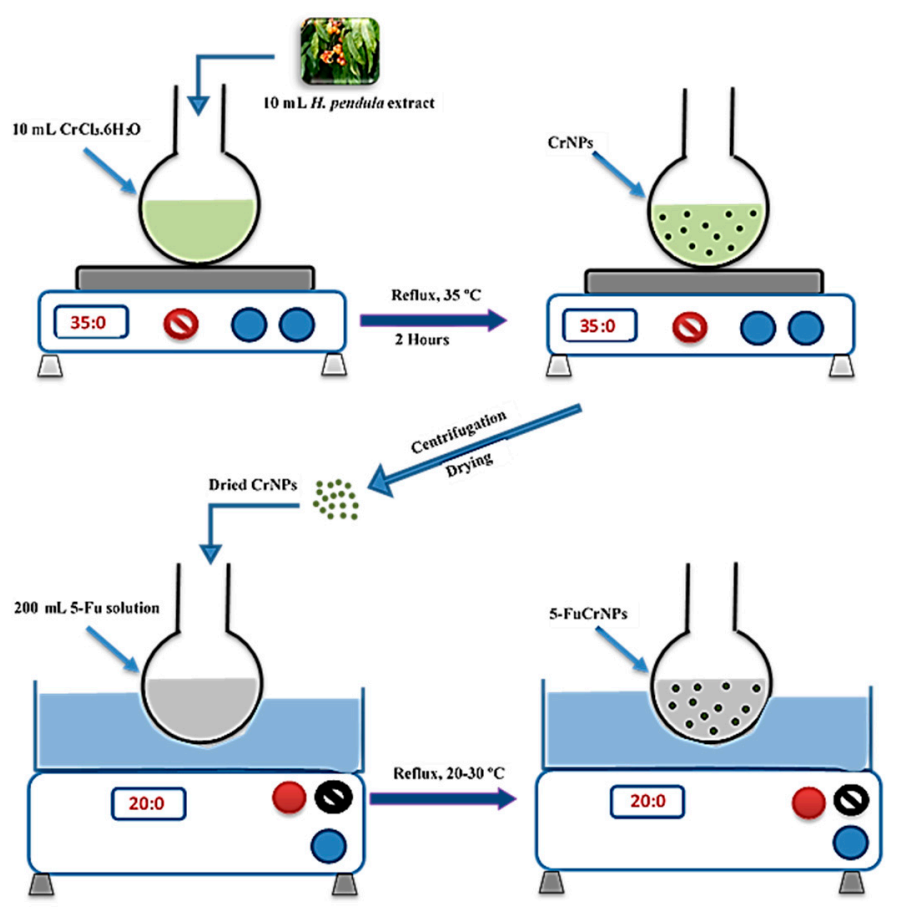

Figure 1. Schematic diagram showing the details of green biosynthesis preparation method, where, (CrNPs) is Chromium nanoparticles, (5-Fu) 5-Fluorouracil, and (5-FuCrNPs) 5-Fluorouracil chromium nanoparticles.

In the present work, the biosynthesized chromium nanoparticles were further loaded with 5-Fu and their anti-tumor activity was evaluated against the CACO-2 cell line. The biosynthesized CrNPs and 5-Fu-loaded chromium NPs were further characterized as described in the following subheadings.

\subsection{XRD Diffraction of the Biosynthesized CrNPs}

The spectrum of XRD comprises three clearly distinguishable peaks. They can all be indexed exactly, not only in the peak position, but also in their relative intensity to crystalline CrNPs. Peaks with $2 \theta$ values of $25.39^{\circ}, 53.21^{\circ}$, and $73.30^{\circ}$ correspond to the crystal planes of crystalline CrNPs (111), (200) and (311), respectively [24]. Scherer's formula (Equation (3) can be used to predict the crystallite sizes [49-52].

$$
D=k \lambda / \beta \cos \theta
$$

where $\lambda$ is the $\mathrm{X}$-ray wavelength, the constant $k$ is 0.94 , and $\theta$ and $\beta$ are half of the Bragg angle and the half-width of the peak, respectively. By using Equation (3), the crystallite sizes were estimated to be approximately $25.5 \mathrm{~nm}$ (Figure 2a). 


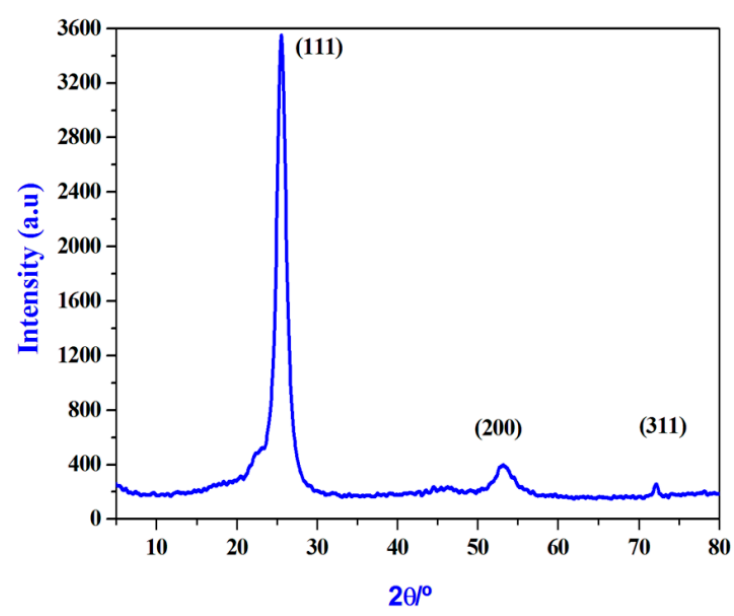

(a)

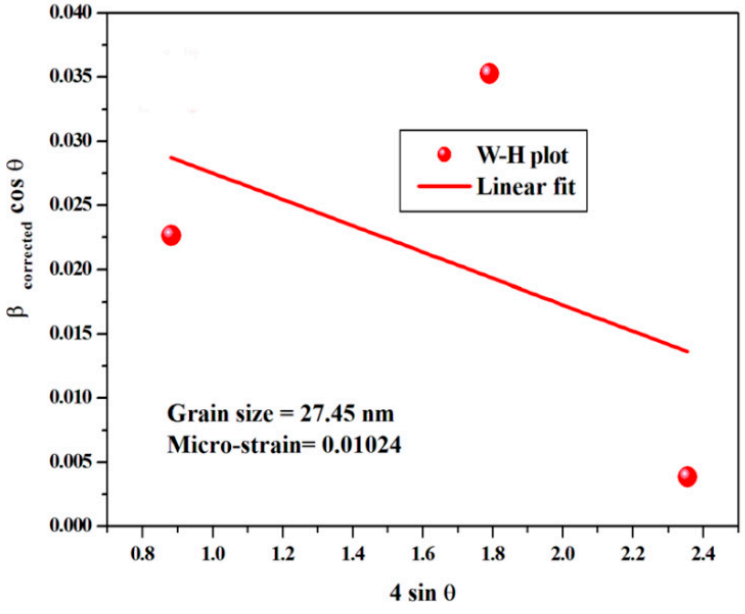

(b)

Figure 2. (a). X-ray powder diffraction (XRD) patterns of the prepared CrNPs. (b). The Williamson-Hall (W-H) plots for CrNPs. The calculations of $\left(\beta_{\text {correct }}\right)$ were carried out according to Psd-Voigt distribution functions.

Analyzing the X-ray peak profile of the prepared CrNPs with the Williamson-Hall (W-H) method allows the crystallite size (i.e., coherently diffracting domains) and the lattice strain (i.e., the lattice parameters resulting from crystal imperfections) to be determined by observing the peak width as a function of the 2-Theta angle $[53,54]$. The corrected expansion of a peak $\beta_{\text {Correct }}$ is connected to the observed expansion $\beta_{\text {Correct }}$ and the instrumental expansion $\beta_{\text {Instrumental }}$ by the following relation (Equation (4)), according to the Lorentzian distribution feature.

$$
\beta_{\text {Correct }}=\beta_{\text {Observed }}-\beta_{\text {Instrumental }}
$$

To measure the pure extension of the XRD lines of our investigated CrNP samples, the observed line integral breadth was used. After the Lorentzian fitting of the spectral XRD peaks in Figure 2b, the line integral breadth for a specific peak is calculated from the integral normalized by the maximum intensity of that peak. As a standard reference material (SRM), the XRD profile of a strongly crystalline LaB6 (660a) was used to measure the instrumental broadening correction in which the expansion effect due to particle size is small. The broadening of the diffraction peaks is attributable to crystallite size $\left(\beta_{D}\right)$ and micro-strain $\left(\beta_{\varepsilon}\right)$ contributions, according to the $(\mathrm{W}-\mathrm{H})$ approach.

Thus, the pure peak broadening $\left(\beta_{\text {Correct }}\right)$ for the sample in the understudy read (Equations (5) and (6)) [55]:

$$
\begin{gathered}
\beta_{\text {Correct }}=\beta_{D}-\beta_{\varepsilon}=\frac{k \lambda}{D \cos \theta}+4 \varepsilon \tan \theta \\
\beta_{\text {Correct }} \cos \theta=\frac{k \lambda}{D_{L}}+4 \varepsilon_{L} \sin \theta
\end{gathered}
$$

where $k$ is the form factor $(\sim 0.94), \lambda$ is the XRPD wavelength of the incident $(\sim 0.15418 \mathrm{~nm})$, $D_{L}$ is the mean size of the crystallite, and $\varepsilon_{L}$ is the average micro-strain. Equation (6) suggests the isotropic existence of the sample and the micro-strain is identical in all crystallographic $(h k l)$ planes. This equation is the uniform model of deformation (UDM), in which the crystal is isotropic in nature $[54,55]$. For the prepared CrNPs, the average crystallite size $\left(D_{L}\right)$ and average micro-strain $\left(\varepsilon_{L}\right)$ were determined using Equation (4). Equation (4) is the linear regression between $\left(\beta_{\text {correct }} \cos \theta\right)$ and $(4 \sin \theta)$, whereas as shown in Figure $2 b$, the $D_{L}(27.45 \mathrm{~nm})$ and $\varepsilon_{L}\left(10.24 \times 10^{-3}\right)$ can be determined from the intercept and slope. 


\subsection{SEM and TEM Analyses of Biosynthesized CrNPs and 5-FuCrNPs}

In the microstructural characterization studies, the size of the nanoparticles was determined, and the homogeneity and size distribution were examined. The particles were found to be nearly spherical, monodispersed, and smooth on the surface (cf. Figure 3a-c). In order to distinguish the morphology, scale, and shape of the nanoparticles, the biosynthesized CrNPs were also characterized by TEM. TEM images of the synthesized CrNPs were measured in the $23 \mathrm{~nm}$ range (Figure 4), where the $29 \mathrm{~nm}$ range of 5-FuCrNPs was measured (Figure 5). TEM images, with the distributions of particle size are shown by the histogram curves (Figures 4 and 5). It can be inferred that in all cases, the spherical CrNPs demonstrated irregular morphologies and poly-dispersed characteristics with a nano-size up to $23 \mathrm{~nm}$. The data of particle size obtained from TEM are correlated with the XRD analysis in Figure 2a.

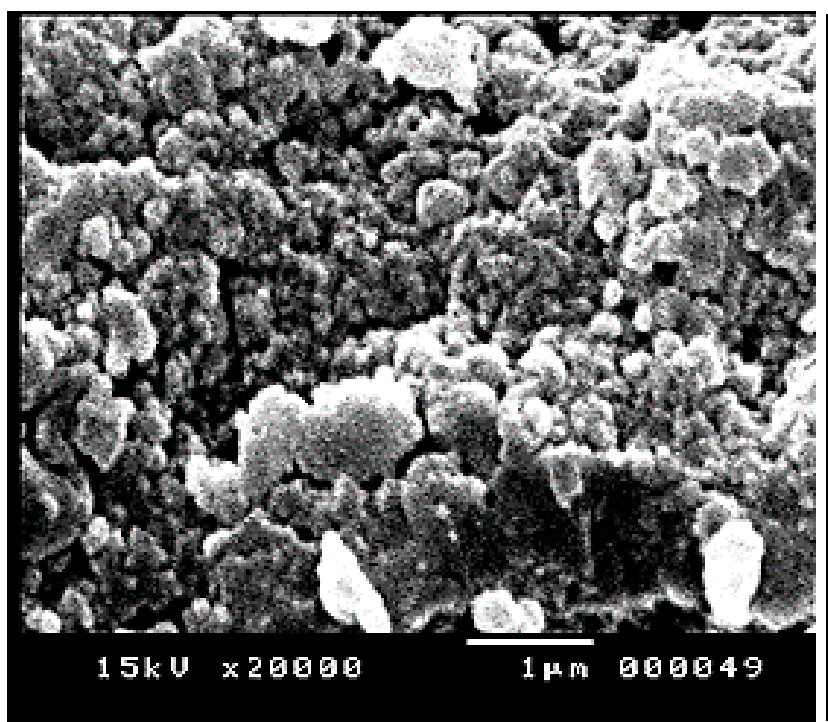

(a)

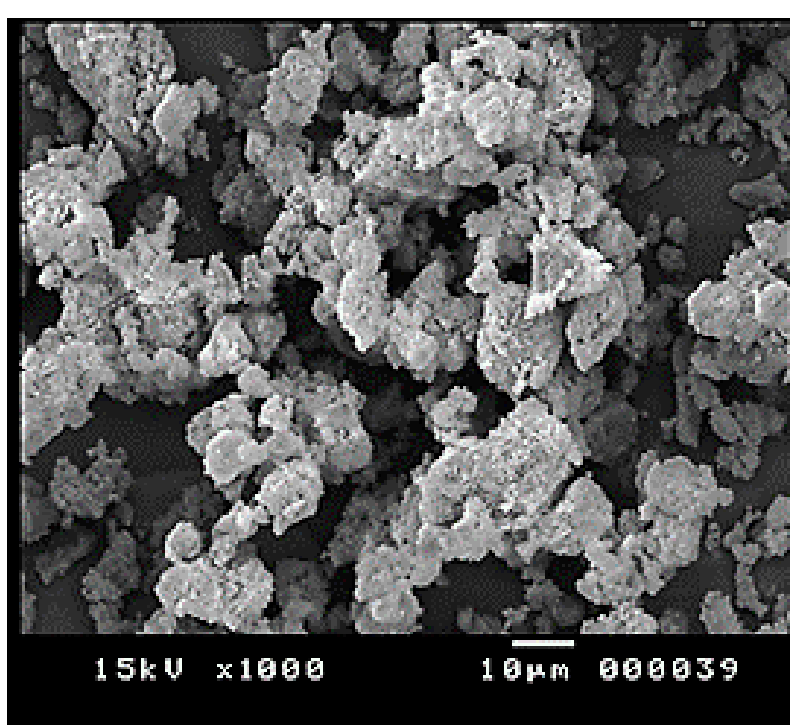

(b)

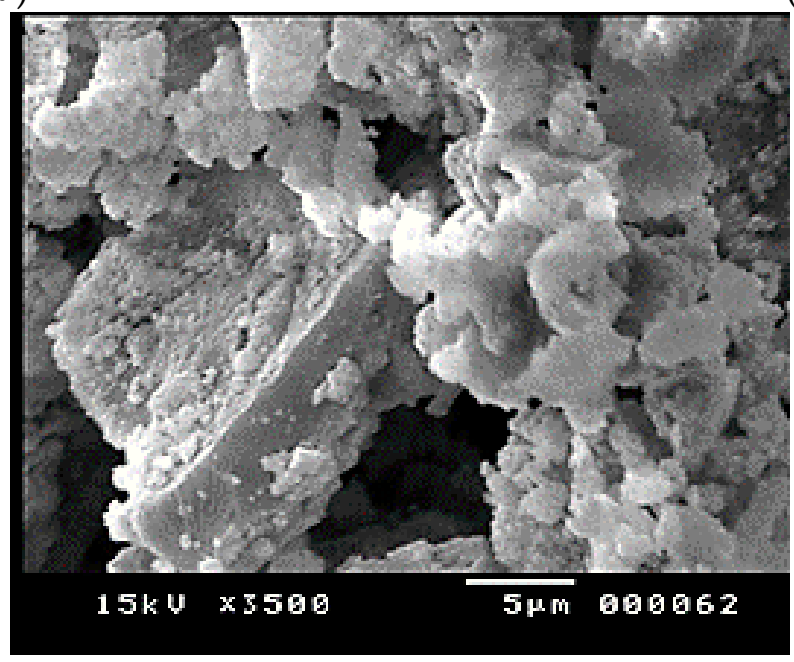

(c)

Figure 3. Scanning electron micrographs of the prepared (a) CrNPs, (b) 5-FuCrNPs N1 and (c) N10. 

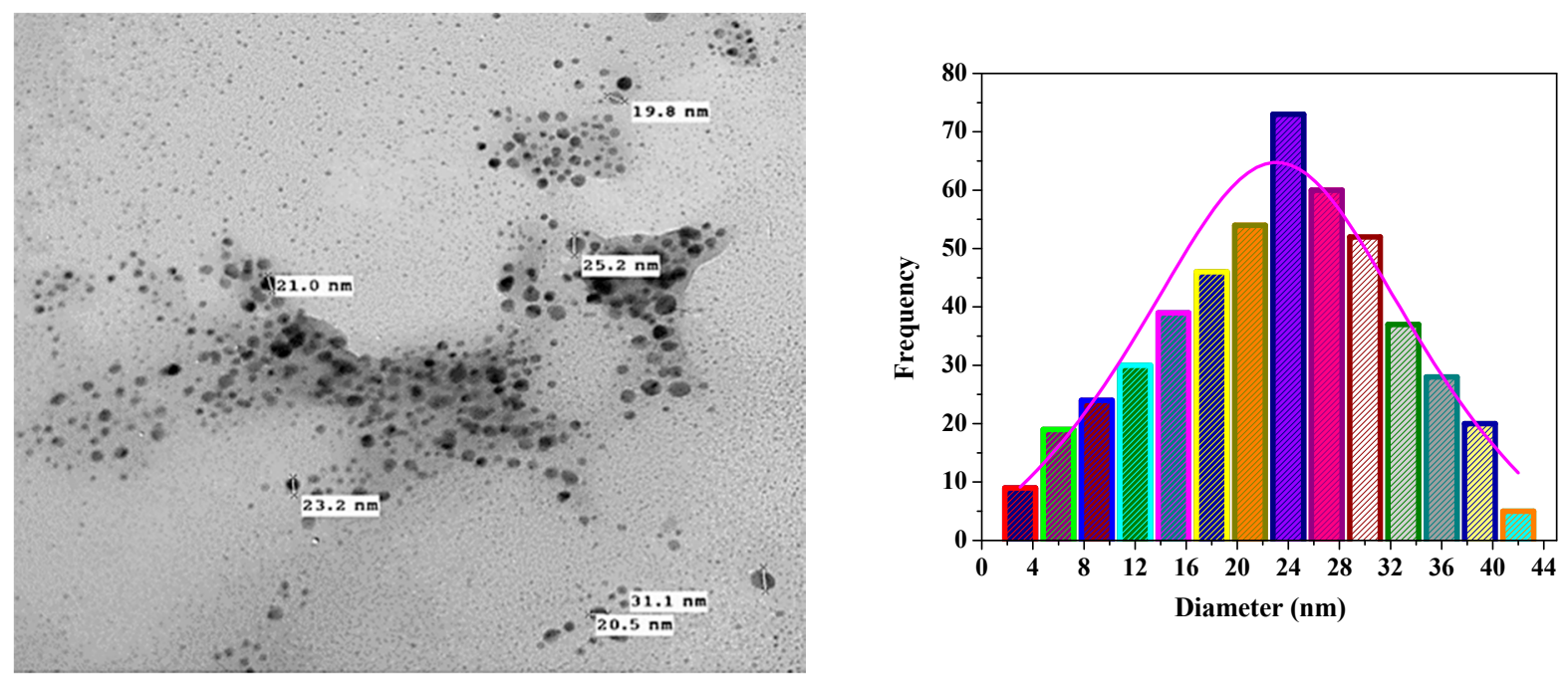

Figure 4. Transmission electron microscope analysis of the prepared CrNPs with a diameter distribution histogram.
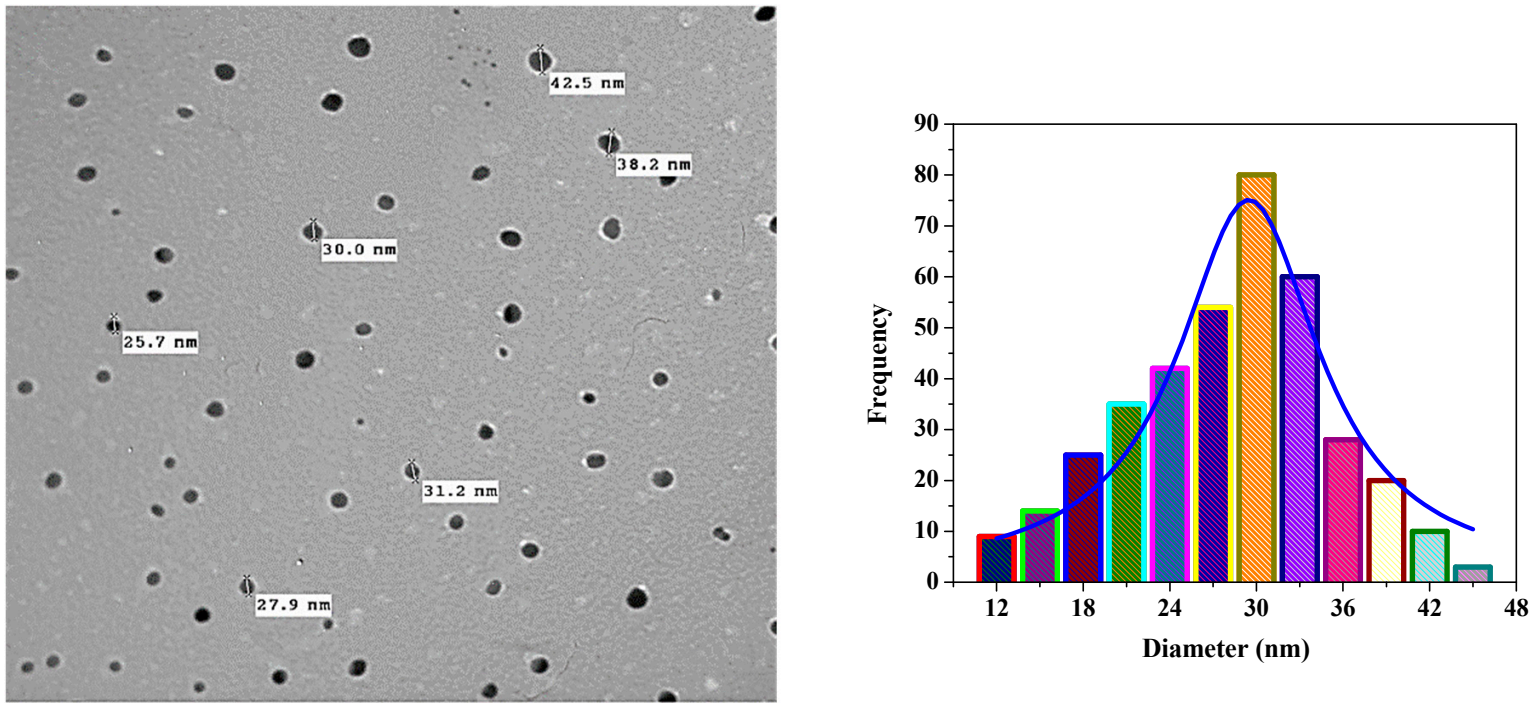

Figure 5. Transmission electron microscope analysis of the prepared 5-FuCrNPs with a diameter distribution histogram.

\subsection{Functional Groups Identification Utilizing FTIR Spectroscopy}

In order to determine the purity and nature of the $\mathrm{Cr}$ nanoparticles and to confirm the encapsulation of 5-Fu over the CrNPs, FTIR spectroscopy was carried out (Figure 6). The peak between 3346 and $1702 / \mathrm{cm}$ is due to the $-\mathrm{OH}$ stretching and bending vibrations of adsorbed water molecules in the sample [56]. At $2383 / \mathrm{cm}$, the characteristic absorption peak may have arisen from the primary amines present in the aqueous extract of the H. pendula [56]. The band at $1733 / \mathrm{cm}$ indicates evidence for the ester group [57]. The two absorption peaks observed at around $570 / \mathrm{cm}$ may be due to the partial amine or carboxyl group deutrization. The absorption peak is characteristic of $\mathrm{OH}$ plane bending at $1388 / \mathrm{cm}$ [58]. The peak at 2930 and $2860 / \mathrm{cm}$ may be due to $-\mathrm{CH}_{2}$ stretching vibrations [59]. C-H stretching in the long aliphatic chain of the fatty acid moiety is associated with peaks at 1442 and $762 / \mathrm{cm}$ [59]. The peaks appearing at 1727 and 1370/cm denote the $\mathrm{C}=\mathrm{O}$ and $\mathrm{C}-\mathrm{O}$ stretching vibrations, respectively, especially for 5 -FuCrNPs. As per the aforementioned discussion, $\mathrm{N}-\mathrm{H}, \mathrm{O}-\mathrm{H}, \mathrm{A}-\mathrm{OH}$ hydroxyl, aliphatic $\mathrm{C}-\mathrm{H}$ stretching bonds are the peaks formed in the extract that are responsible for reducing $\mathrm{Cr}(\mathrm{III})$ to $\mathrm{CrNPs}$ in these extracts. These biomolecules can act as agents of reduction and stabilization [24]. 


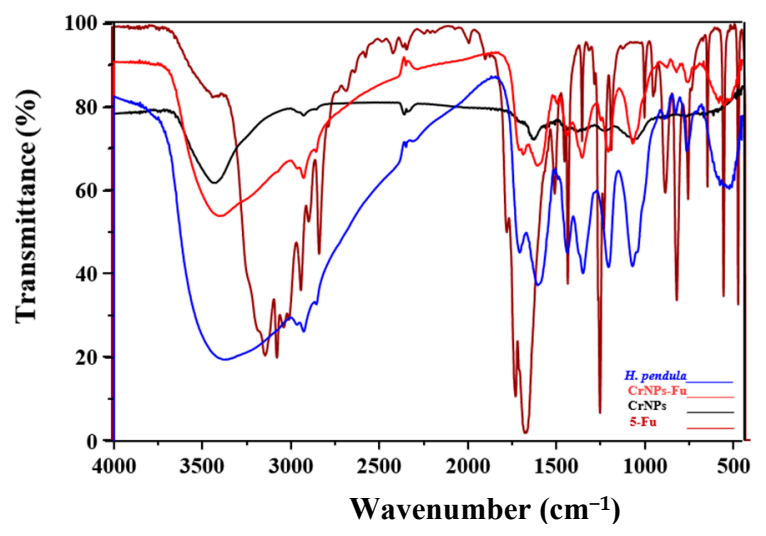

Figure 6. Fourier transform infrared spectra of the prepared CrNPs, 5-FuCrNPs, H. pendula extract, and $5-\mathrm{Fu}$.

\subsection{Drug Loading Efficiency on CrNPs (LE\%)}

The effects of independent variables on the LE\%, and drug release after 1 and $3 \mathrm{~h}$ are listed in Table 1. Regarding the 5-Fu concentration, the calculated theoretical drug content value for N1, N5, and N12 was 20\%, while for N2, N3, N7, N8, N9, N13 and 14 it was 33.33\% and for N4, N10, N11, and N15 it was $42.85 \%$. The effect of changing the 5-Fu concentration on the LE\% was investigated, at each 5-Fu concentration, $\mathrm{CrNP}$ weight and temperature, using the ANOVA test. The LE\% depends on the 5-Fu concentration, CrNP weight and temperature, and ranges from $55.87 \pm 2.03 \%$ to $92.11 \pm 3.23 \%$. The regression Equation (7) of the fitted LE\% model is $[36,42]$ :

$L E \%=79.45+7.21 X_{1}+6.45 X_{2}-4.99 X_{3}-1.19 X_{1}^{2}-5.24 X_{2}^{2}+2.25 X_{3}^{2}-1.31 X_{1} X_{2}+0.57 X_{1} X_{3}-0.14 X_{2} X_{3}$

Since the $p$-value in the ANOVA table is less than 0.1 , there is a statistically significant relationship between the variables at the $90 \%$ and higher confidence level. The R-squared statistic indicates that the model (as fitted) explains $36.23 \%$ of the variability in 5-Fu concentration. However, the output shows the results of fitting a multiple linear regression model to describe the relationship between CrNP weight and the LE\%. Since the $p$-value is less than 0.1 , there is a statistically significant relationship between the variables at the $90 \%$ confidence level. The R-squared statistic indicates that the model (as fitted) explains $37.87 \%$ of the variability in CrNP weight. The temperature had a non-significant effect on the $\mathrm{LE} \%$, as $p$-value is greater than 0.1 , in spite of the decrease in LE\% with the increase in temperature.

The 3D plot (Figure 7) showed that the LE\% increased from $55.87 \pm 2.03$ to $74.32 \pm 2.08$ and from $80.25 \pm 2.21$ to $92.11 \pm 3.23$ at lower and higher 5 -Fu concentrations with a constant CrNP weight and temperature. The improvement in LE\% with increased speed levels was due to the fact that more of the drug is adsorbed and incorporated on the surface of CrNPs with a high 5-Fu concentration. A linear relationship between the two variables investigated the percentage drug incorporation. The biosynthesis of 5-FuCrNPs involves two major steps, the formation of stable CrNPs of the $\mathrm{CrCl}_{3}$ solution and the subsequent adsorption of 5-Fu on the surface of the CrNPs. These two steps have a significant effect on the size and $\mathrm{LE} \%$ of nanoparticles prepared. Similar results were obtained for the preparation of biodegradable sorafenib-loaded carbon nanotubes for the treatment of hepatocellular carcinoma (HCC) [39]. 


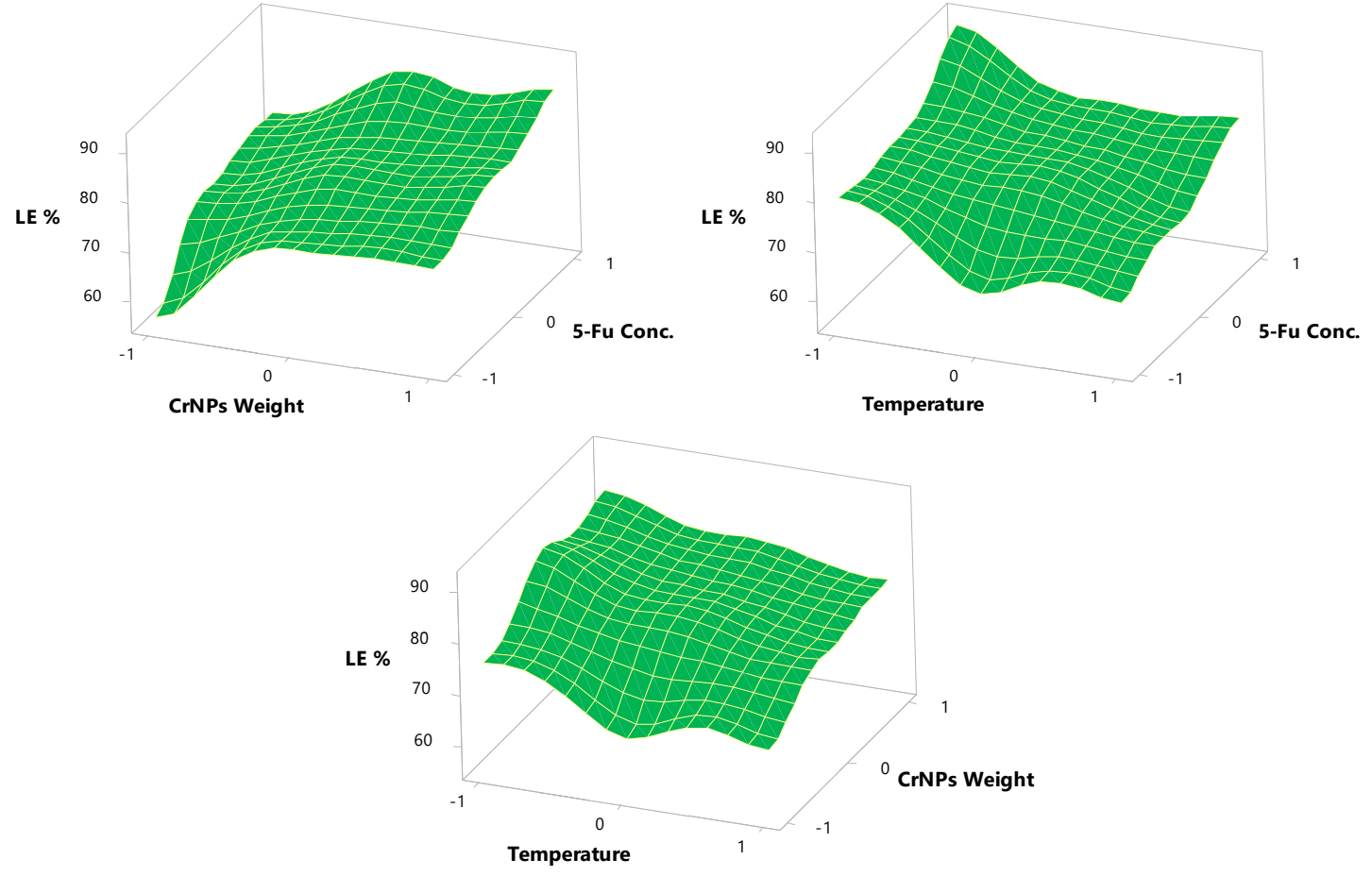

Figure 7. Surface plots effects of different formulation factors on $\mathrm{LE} \%$.

Alternatively, the LE\% increased from $75.64 \pm 3.98$ to $85.89 \pm 2.01$ and $74.32 \pm 2.08$ to $87.54 \pm 2.02 \%$ at lower and higher CrNP weights with a constant 5 -Fu concentration and temperature (Table 1). As the weight of the CrNPs increased, the surface area available for drug loading was increased. This increase in surface area allows more drug to be adsorbed on the surface of the nanoparticles.

The temperature degrees selected during nanoparticle preparation had a noticeable effect on the LE\% of the drug; as the temperature increased, the LE\% decreased. These results were expected, as the adsorption process of the drug on the surface of the CrNPs decreased with increasing the temperature of the reflux process of 5-Fu with CrNPs [60]. The main target of studying the temperature effect was to achieve the optimum reflux temperature that yields a higher LE\%. The LE\% decreased from $75.64 \pm 3.98$ to $67.31 \pm 2.23 \%$ (N2, N3) and from $80.25 \pm 2.21$ to $67.76 \pm 3.05 \%(\mathrm{~N} 5, \mathrm{~N} 6)$ at lower and higher levels of temperature with a constant 5-Fu concentration and CrNPs weight (Table 1). All these results confirm that to obtain higher values of $\mathrm{LE} \%$, a lower temperature should be used $\left(20 \pm 1{ }^{\circ} \mathrm{C},-1\right)$.

\subsection{In Vitro Release Study of 5-FuCrNPS}

Regression Equations (8) and (9) show the output of the relationship between 5-Fu concentration, CrNP weight, and temperature with the percentage drug released after 1 and $3 \mathrm{~h}$.

$$
\begin{aligned}
& \operatorname{Rel} 1 \mathrm{~h}=16.10+3.365 \mathrm{X}_{1}-2.420 \mathrm{X}_{2}+0.527 \mathrm{X}_{3}-3.38 \mathrm{X}_{1}^{2}+2.31 \mathrm{X}_{2}^{2}+1.27 \mathrm{X}_{3}^{2}-0.21 \mathrm{X}_{1} \mathrm{X}_{2}+0.19 \mathrm{X}_{1} \mathrm{X}_{3}-1.18 \mathrm{X}_{2} \mathrm{X}_{3} \\
& \operatorname{Rel} 3 \mathrm{~h}=84.73+7.37 \mathrm{X}_{1}-2.27 \mathrm{X}_{2}-1.15 \mathrm{X}_{3}-5.35 \mathrm{X}_{1}^{2}-7.47 \mathrm{X}_{2}^{2}+2.86 \mathrm{X}_{3}^{2}-3.37 \mathrm{X}_{1} \mathrm{X}_{2}+2.06 \mathrm{X}_{1} \mathrm{X}_{3}-5.05 \mathrm{X}_{2} \mathrm{X}_{3}
\end{aligned}
$$

The 5-Fu concentration, as well as CrNP weight, has a significant effect on drug release ( $p$-value $<0.1$ ), after 1 and $3 \mathrm{~h}$. The drug release percentage increases with an increase in their levels. In contrast to its effect on the LE\%, the temperature had a non-significant effect on drug release.

Table 1 and Figures 8 and 9 show the response surface plots of the in vitro release of 5-Fu from its CrNPs. The results show the in vitro release of 5-Fu from formulae (N1, N2, N3, and N4) using CrNPs $\left(\mathrm{X}_{2}\right)$ at a constant level $(-1)$ with variable 5-Fu concentrations 
$\left(\mathrm{X}_{1}\right), 0.25 \%$ for $\mathrm{N} 1 ; 0.5 \%$ for $\mathrm{N} 2, \mathrm{~N} 3$, and $0.75 \%$ for $\mathrm{N} 4 ;\left(\mathrm{X}_{2}\right)$. The maximum and minimum percent released was observed to be $14.88 \pm 1.88$ and $24.12 \pm 1.77 \%$ at the end of $1 \mathrm{~h}\left(\mathrm{Y}_{2}\right)$. The maximum and minimum in vitro release after $3 \mathrm{~h}\left(\mathrm{Y}_{3}\right)$ of dissolution was $90.77 \pm 1.72$ and $62.15 \pm 1.96 \%$, respectively. These investigated formulae can be arranged, in descending order, concerning the in vitro release within $3 \mathrm{~h}$ as follows: N3 $>\mathrm{N} 2>\mathrm{N} 4>$ $\mathrm{N} 1$, respectively.
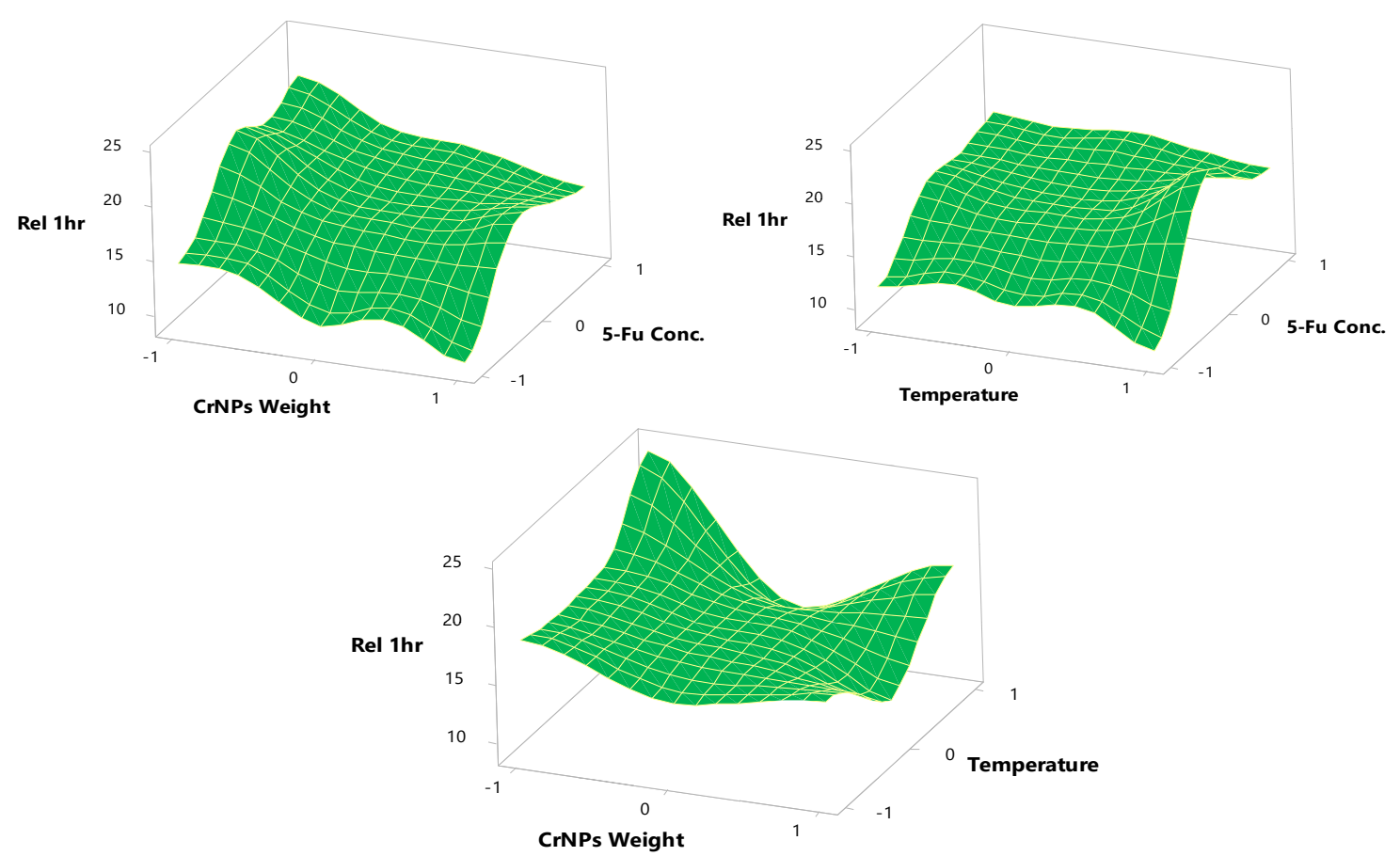

Figure 8. Surface plots effects of different formulation factors on Release after one hour.
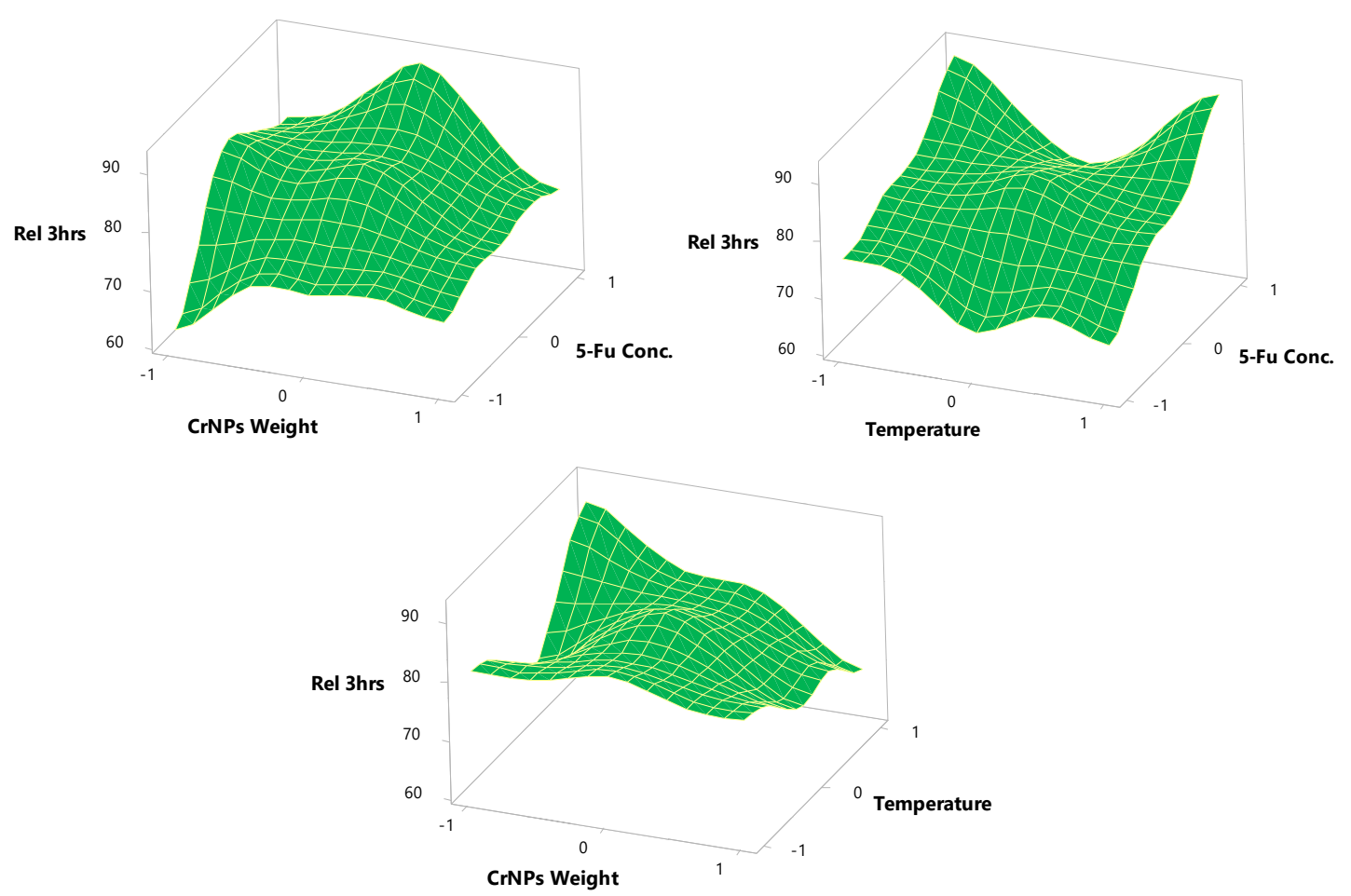

Figure 9. Surface plots effects of different formulation factors on release after $1 \mathrm{~h}$. 
The data for the in vitro release of 5-Fu from the CrNPs containing formulae N5, N6, N7, N8, N9, N10, and N11 using constant CrNP weight $\left(X_{2}\right)$ at the medium level (0), variable temperature levels (ranging from -1 to +1 ), and with variable 5 -Fu concentrations $\left(\mathrm{X}_{1}\right)$ are shown in Table 1. The maximum and minimum percentages released were $18.33 \pm 1.43$ and $11.89 \pm 1.98 \%$ at the end of $1 \mathrm{~h}\left(\mathrm{Y}_{2}\right)$. The maximum and minimum in vitro release after $3 \mathrm{~h}$ of dissolution $\left(\mathrm{Y}_{3}\right)$ were found to be $92.73 \pm 1.33$ and $76.09 \pm 1.94 \%$, respectively. According to these results, these formulae can be arranged, in descending order, concerning the in vitro release within $3 \mathrm{~h}$ dissolution as follows: $\mathrm{N} 11>\mathrm{N} 10>\mathrm{N} 7>\mathrm{N} 8>\mathrm{N} 9>\mathrm{N} 5>$ N6, respectively.

The in vitro release of 5-Fu from the CrNPs containing formulae N12, N13, N14, and N15 was examined using constant CrNPs weight $\left(X_{1}\right)$ at the medium level (0), variable temperature levels (ranging from -1 to +1 ), and with variable 5-Fu concentrations $\left(\mathrm{X}_{1}\right)$.

The significant negative effect of CrNP weight on drug release after 1 and $3 \mathrm{~h}$ is obvious at different formulations, as revealed by Equations (8) and (9). At a constant 5-Fu concentration $\left(X_{1}\right)$ and temperature $\left(X_{3}\right)(0,1)$, the percentage of 5-Fu released was $24.12 \pm 1.77$ and $18.61 \pm 1.66 \%(\mathrm{~N} 3, \mathrm{~N} 14)$ at the end of $1 \mathrm{~h}\left(\mathrm{Y}_{2}\right)$ at lower and higher CrNP weights. The maximum and minimum in vitro release after $3 \mathrm{~h}$ of dissolution $\left(\mathrm{Y}_{3}\right)$ was found to be $90.77 \pm 1.72$ and $69.93 \pm 1.54 \%$. The same findings were shown for N4 and $\mathrm{N} 15$ at lower and higher CrNP weights, as the percentage was released after $1 \mathrm{~h}$ decreased from $21.90 \pm 1.65$ to $15.92 \pm 1.99 \%$, and after $3 \mathrm{~h}$ from $79.42 \pm 1.33$ to $74.18 \pm 1.63 \%$.

All these results revealed the significant effect of increasing the 5-Fu concentration on the release of the drug after 1 and $3 \mathrm{~h}$. These findings are correlated to the ease of drug release as it adsorbed on the surface of CrNPs and a greater amount of the drug is available for release with increasing its concentration. The amount released after $1 \mathrm{~h}$ was small compared to the amount released after $3 \mathrm{~h}$. These results may be due to the difficulty of desorption of 5-Fu from CrNPs in the acidic environment and the nature of the prepared 5-FuCrNP system, which is still intact at a pH of 1.2. At an alkaline $\mathrm{pH}$, the drug undergoes fast desorption behavior, and the amount released increased dramatically due to the basic nature of the 5-Fu and coated CrNPs that allows for a greater amount of the drug to be available for absorption sites. These results are valuable for decreasing the incidence of gastritis and the other 5-Fu side effects by decreasing drug release in the stomach. In addition to increasing drug bioavailability at absorption sites in the intestine, the green biosynthesis of CrNPs decreases $\mathrm{Cr}$ toxicity and enhances its clearance from the body by conjugation with bile salts.

The percentage of drug released was inversely proportional to CrNP weight. These results are in accordance with the fact that an increase in CrNP surface area with increasing NP weight allows more drug to be adsorbed on the surface on the monolayer pattern. This monolayer attachment of 5-Fu exerts a negative effect on the release of the drug from the CrNP surface. In contrast, as the CrNP weight was decreased, the amount of drug adsorbed in a multilayer pattern on the surface of CrNPs that makes it more easily released due to attachment forces was decreased.

In contrast to $\mathrm{LE} \%$, temperature had a non-significant effect on 5 -Fu release after 1 and $3 \mathrm{~h}$. The results of LE\% on in vitro release after 1 and $3 \mathrm{~h}$ revealed that the optimum selected formula of 5-FuCrNPs should be prepared at a high level of 5-Fu concentration $(+1,0.75 \%)$, medium level of CrNP weight $(0,500 \mathrm{mg})$ and low level of temperature $(-1$, $20 \pm 1^{\circ} \mathrm{C}$ ). According to the rank order of all formulae (considering the higher LE\% and Rel. 1 and $3 \mathrm{~h}$ ), the optimum formula is N10, while the remaining formulae ranked as follows: N11, N3, N13, N8, N2, N4, N7, N15, N9, N14, N5, N12, N1, and finally, N6. The optimum formula $\mathrm{N} 10\left(+1,0\right.$, and -1 for $X_{1}, X_{2}$, and $\left.X_{3}\right)$ was selected for further cell viability study and antitumor activity study on the colorectal cell line (CACO-2).

\subsection{In Vitro Cytotoxicity Assay}

The cytotoxic effect of 5-FuCrNPs on CACO cells was investigated using the MTT assay and this was compared with that of 5-Fu alone. Both 5-Fu and 5-FuCrNPs exerted a 
dose-dependent cytotoxic effect (Figure 10a). Interestingly, 5-FuCrNPs markedly decreased the IC50 of 5-Fu from 106 to $19.7 \mu \mathrm{g} / \mathrm{mL}$. Supporting our data, flow cytometry analysis showed that when cells were treated with 5-FuCrNPs $(30 \mu \mathrm{g} / \mathrm{mL})$, more late apoptotic cells were observed $(42.7 \%)$ compared to cells treated with the same concentration of 5-Fu $(20 \%)$ or CrNPs alone (11.7\%) (Figure 10b-d).
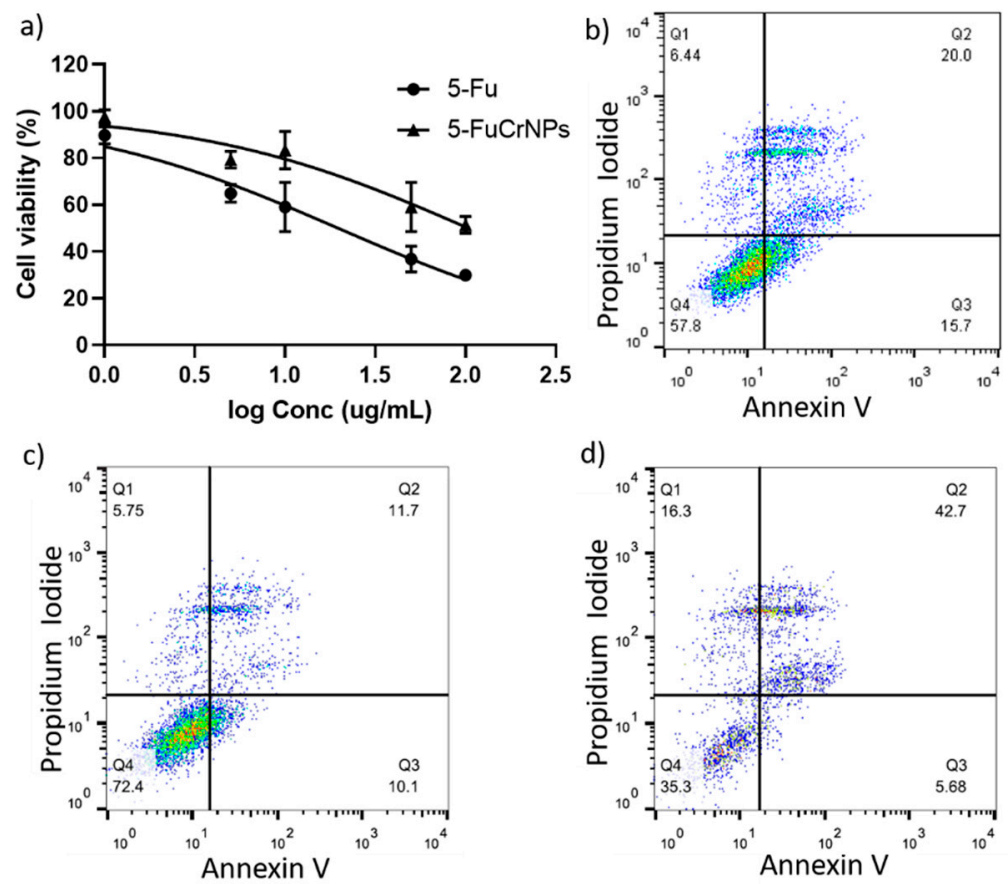

Figure 10. Viability of the CACO cells treated with different concentrations of 5-Fu and 5-FuCrNPs determined by the MTT assay (a). Flow cytometry analysis showing the frequency of apoptotic cells treated with 5-Fu (b), CrNPs (c), and 5-FuCrNPs (d).

The toxicity of chromium is attributed to its conversion to chromium (III) by $\mathrm{OH}$ - after passing through the ion channels of the cytoplasmic membrane generation [61]. Our results demonstrate that the toxicity of 5-FuCrNPs in CACO cells was dose-dependent and achieved better results than 5-Fu alone, as measured by the cellular reduction in MTT [62,63].

Similarly, chromium oxide nanoparticles exert significant cytotoxic activity on murine fibrosarcoma cells (L929) [63]. Chromium can induce cytotoxicity by different mechanisms. Xia, et al. [64] showed that cells treated with chromium suffer from increased DNA damage, such as mutations, including double- and single-strand breaks at minute damage sites of DNA [62]. In addition, exposure to chromium nanoparticles has been associated with enhanced intracellular reactive oxygen species and oxidative stress, pointing to the induction of apoptosis. Thia was also associated with decreased glutathione levels and lipid peroxidation $[65,66]$. Interestingly, treatment with chromium resulted in elevated expression of autophagy-related proteins such as Beclin1 and LC3II [67].

\section{Conclusions}

Chromium nanoparticles were prepared using a novel green biosynthesis methodology and successively loaded with 5-Fu. Photographs of SEM and TEM images revealed that the prepared 5-FuCrNPs were spherical in shape, with a smooth surface and have an optimum nanosized range for drug delivery to tumor tissues. All formulation parameters (5-Fu concentration, CrNP weight and temperature) had significant effects on the LE\%. CrNPs loaded with 5-Fu could be a promising agent for the effective treatment of colorectal cancer as we demonstrated that they markedly decreased the IC50 of 5-Fu and exerted greater cytotoxicity than 5-Fu alone. Based on our interesting findings, we recommended 
the future use of the 5-FuCrNP combination to overcome clinical resistance and decrease the toxic effects on the bone marrow that are associated with a high dose of 5-Fu.

Author Contributions: Conceptualization, M.S.S. and M.M.A.E.; methodology, M.S.S., M.A.E.-M., M.F.A.-H., M.M.A.E., H.S.F., H.A.A.-T., M.S.A.A. and A.M.A.-D.; software, M.M.A.E.; validation, M.M.A.E., M.F.A.-H., M.M.A.E., H.S.F., H.A.A.-T. and J.A.A.-A. and A.M.A.-D.; formal analysis, M.M.A.E.; investigation, M.S.S., M.A.E.-M., M.S.A.A., M.F.A.-H., M.M.A.E., H.S.F., H.A.A.-T. and J.A.A.-A. and A.M.A.-D.; resources, M.S.S.; data curation, M.M.A.E.; writing-original draft preparation, M.S.S.; writing—review and editing, M.M.A.E.; visualization, J.A.A.-A.; supervision, M.M.A.E., M.S.S. and H.A.A.-T.; project administration, M.S.S. and M.M.A.E. All authors have read and agreed to the published version of the manuscript.

Funding: This research received no external funding.

Institutional Review Board Statement: Not applicable.

Informed Consent Statement: Not applicable.

Data Availability Statement: Not applicable.

Conflicts of Interest: The authors declare no conflict of interest.

\section{References}

1. Rawla, P.; Sunkara, T.; Barsouk, A. Epidemiology of colorectal cancer: Incidence, mortality, survival, and risk factors. Prz. Gast. 2019, 14, 89-103. [CrossRef] [PubMed]

2. O'Leary, M.P.; Choong, K.C.; Thornblade, L.W.; Fakih, M.G.; Fong, Y.; Kaiser, A.M. Management considerations for the surgical treatment of colorectal Cancer during the global Covid-19 pandemic. Ann. Surg. 2020, 272, e98-e105. [CrossRef] [PubMed]

3. Schuhmacher, C.; Gretschel, S.; Lordick, F.; Reichardt, P.; Hohenberger, W.; Eisenberger, C.F.; Haag, C.; Mauer, M.E.; Hasan, B.; Welch, J. Neoadjuvant chemotherapy compared with surgery alone for locally advanced cancer of the stomach and cardia: European Organisation for Research and Treatment of Cancer randomized trial 40954. J. Clin. Oncol. 2010, 28, 5210-5218. [CrossRef]

4. Baskar, R.; Lee, K.A.; Yeo, R.; Yeoh, K.-W. Cancer and radiation therapy: Current advances and future directions. Int. J. Med Sci. 2012, 9, 193-199. [CrossRef]

5. Rebucci, M.; Michiels, C. Molecular aspects of cancer cell resistance to chemotherapy. Biochem. Pharmacol. 2013, 85, 1219-1226. [CrossRef] [PubMed]

6. Vodenkova, S.; Buchler, T.; Cervena, K.; Veskrnova, V.; Vodicka, P.; Vymetalkova, V. 5-fluorouracil and other fluoropyrimidines in colorectal cancer: Past, present and future. Pharm. Therap. 2020, 206, 107447. [CrossRef]

7. de Gramont, A.d.; Figer, A.; Seymour, M.; Homerin, M.; Hmissi, A.; Cassidy, J.; Boni, C.; Cortes-Funes, H.; Cervantes, A.; Freyer, G. Leucovorin and fluorouracil with or without oxaliplatin as first-line treatment in advanced colorectal cancer. J. Clin. Oncol. 2000, 18, 2938-2947. [CrossRef]

8. Nair, L.; Jagadeeshan, S.; Nair, S.A.; Kumar, G.V. Biological evaluation of 5-fluorouracil nanoparticles for cancer chemotherapy and its dependence on the carrier, PLGA. Int. J. Nanomed. 2011, 6, 1685-1697. [CrossRef]

9. Braun, M.S.; Seymour, M.T. Balancing the efficacy and toxicity of chemotherapy in colorectal cancer. Ther. Adv. Med Oncol. 2010, 3, 43-52. [CrossRef]

10. He, Y.-C.; Chen, J.-W.; Cao, J.; Pan, D.-Y.; Qiao, J.-G. Toxicities and therapeutic effect of 5-fluorouracil controlled release implant on tumor-bearing rats. World J. Gastroenterol. 2003, 9, 1795-1798. [CrossRef]

11. Wilkinson, J. Nanotechnology applications in medicine. Med. Dev. Technol. 2003, 14, 29.

12. Jameel, A.T.; Yaser, A.Z. Advances in Nanotechnology and Its Applications; Springer: Berlin/Heidelberg, Germany, 2020.

13. Sun, Q.; Zhou, Z.; Qiu, N.; Shen, Y. Rational design of cancer nanomedicine: Nanoproperty integration and synchronization. Adv. Mater. 2017, 29, 1606628. [CrossRef]

14. Qiao, Y.; He, J.; Chen, W.; Yu, Y.; Li, W.; Du, Z.; Xie, T.; Ye, Y.; Hua, S.Y.; Zhong, D. Light-Activatable Synergistic Therapy of Drug-Resistant Bacteria-Infected Cutaneous Chronic Wounds and Nonhealing Keratitis by Cupriferous Hollow Nanoshells. ACS Nano. 2020, 14, 3299-3315. [CrossRef]

15. Saddik, M.S.; Mohamed, E.E.; Elmahdy, M.M. Preparation and Characterization of Niosomal Carrier System of Hydrophilic Drug (Methylene Blue) for Photodynamic Therapy. Lat. Americ J. Pharm. 2020, 39, 561-569.

16. Angelova, A.; Angelov, B. Dual and multi-drug delivery nanoparticles towards neuronal survival and synaptic repair. Neural Regen. Res. 2017, 12, 886-889. [CrossRef]

17. Anderson, R.A. Chromium as an essential nutrient for humans. Regul. Toxicol. Pharmacol. 1997, 26, S35-S41. [CrossRef]

18. Anderson, R.A. Effects of chromium on body composition and weight loss. Nutr. Rev. 1998, 56, 266-270. [CrossRef]

19. Sukumar, C.; Gowthami, G.; Nitya, R.; Janaki, V.; Kamala-Kannan, S.; Shanthi, K. Significance of co-immobilized activated carbon and Bacillus subtilis on removal of Cr (VI) from aqueous solutions. Environ. Earth Sci. 2013, 72, 839-847. [CrossRef] 
20. Medina, C.; Santos-Martinez, M.; Radomski, A.; Corrigan, O.; Radomski, M. Nanoparticles: Pharmacological and toxicological significance. Br. J. Pharm. 2007, 150, 552-558. [CrossRef] [PubMed]

21. Wang, X.; Wang, Y.; Chen, Z.G.; Shin, D.M. Advances of cancer therapy by nanotechnology. Cancer Res. Treat. 2009, 41, 1-11. [CrossRef] [PubMed]

22. Refaat, H.; Naguib, Y.W.; Elsayed, M.; Sarhan, H.A.; Alaaeldin, E. Modified spraying technique and response surface methodology for the preparation and optimization of propolis liposomes of enhanced anti-proliferative activity against human melanoma cell line A375. Pharmaceutics 2019, 11, 558. [CrossRef] [PubMed]

23. Auda, S.H.; Abd El-Rasoul, S.; Ahmed, M.M.; Osman, S.K.; El-Badry, M. In-vitro release and in-vivo performance of tolmetin from different topical gel formulations. J. Pharm. Investig. 2015, 45, 311-317. [CrossRef]

24. Satgurunathan, T.; Bhavan, P.S.; Joy, R.D.S. Green Synthesis of Chromium Nanoparticles and Their Effects on the Growth of the Prawn Macrobrachium rosenbergii Post-larvae. Biol. Trace Element Res. 2018, 187, 543-552. [CrossRef] [PubMed]

25. Saddik, M.S.; Alsharif, F.M.; El-Mokhtar, M.A.; Al-Hakkani, M.F.; El-Mahdy, M.M.; Farghaly, H.S.; Abou-Taleb, H.A. Biosynthesis, Characterization, and Wound-Healing Activity of Phenytoin-Loaded Copper Nanoparticles. AAPS PharmSciTech 2020, 21, 1-12. [CrossRef]

26. Kumar, R.; Ghoshal, G.; Jain, A.; Goyal, M. Rapid green synthesis of silver nanoparticles (AgNPs) using (Prunus persica) plants extract: Exploring its antimicrobial and catalytic activities. J. Nanomed. Nanotechnol. 2017, 8, 1-8.

27. Abboud, Y.; Saffaj, T.; Chagraoui, A.; El Bouari, A.; Brouzi, K.; Tanane, O.; Ihssane, B. Biosynthesis, characterization and antimicrobial activity of copper oxide nanoparticles (CONPs) produced using brown alga extract (Bifurcaria bifurcata). Appl. Nanosci. 2013, 4, 571-576. [CrossRef]

28. Abd El Rasoul, S.; Saleh, K. Emulsion solvent evaporation method for preparing Eudragit RS100 microparticles loaded ketorolac tromethamine. Asian J. Pharm. Health Sci. 2013, 3, 627-639.

29. Dizes, C.; Gerald, F.; Lavaud, C.; Ellas, R.; Faure, R.; Massiot, G.; Balansard, G. Harpuloside a triterpenoid saponin from Harpullia ramiflora. Phytochemistry 1998, 48, 1229-1232. [CrossRef]

30. Poovapatthanachart, R. Phytochemical Study of Harpullia Arborea Leaves. Master's Thesis, Chulalongkorn University, Bangkok, Thailand, 2003.

31. Abdelkader, M.S.A.; Rateb, M.E.; Mohamed, G.A.; Jaspars, M. Harpulliasides A and B: Two new benzeneacetic acid derivatives from Harpullia pendula. Phytochem. Lett. 2016, 15, 131-135. [CrossRef]

32. Ghaly, N.S.; Nabil, M.; Grace, M.H.; Melek, F.R. Pendulaosides A and B. Two acylated triterpenoid saponins from Harpullia pendula seed extract. Phytochem. Lett. 2017, 21, 278-282. [CrossRef]

33. El Souda, S.S.; Mohammed, R.S.; Ibrahim, F.M.; Matloub, A.A. Harpullia pendula Planch leaves: Phenolics, in vitro antioxidant and $\alpha$-amylase inhibitory activity. Egypt. Pharm. J. 2017, 16, 103. [CrossRef]

34. El-Rasoul, A.; Ahmed, M.M. Chitosan polymer as a coat of calcium alginate microcapsules loaded by non-steroidal antiinflammatory drug. Bull. Pharm. Sci. 2010, 33, 179-186. [CrossRef]

35. Ahmed, M.M.; Abd El-Rasoul, S.; Auda, S.H.; Ibrahim, M.A. Emulsification/internal gelation as a method for preparation of diclofenac sodium-sodium alginate microparticles. Saud Pharm. J. 2013, 21, 61-69. [CrossRef] [PubMed]

36. Elsayed, M.M.; Abd El Rasoul, S.; Hussein, A.K. Response Surface Methodology as a Useful Tool for Development and Optimization of Sustained Release Ketorolac Tromethamine Niosomal Organogels. J. Pharm. Innov. 2020, 15, 664-677. [CrossRef]

37. Marques, S.S.; Ramos, I.I.; Fernandes, S.R.; Barreiros, L.; Lima, S.A.; Reis, S.; Domingues, M.R.M.; Segundo, M.A. Insights on Ultrafiltration-Based Separation for the Purification and Quantification of Methotrexate in Nanocarriers. Molecules 2020, $25,1879$. [CrossRef] [PubMed]

38. De la Luz-Asunción, M.; Sánchez-Mendieta, V.; Martínez-Hernández, A.L.; Castaño, V.; Velasco-Santos, C. Adsorption of phenol from aqueous solutions by carbon nanomaterials of one and two dimensions: Kinetic and equilibrium studies. J. Nanomat. 2015, 2015, 405036. [CrossRef]

39. Elsayed, M.M.; Mostafa, M.E.; Alaaeldin, E.; Sarhan, H.A.; Shaykoon, M.S.; Allam, S.; Ahmed, A.R.; Elsadek, B.E. Design and characterisation of novel Sorafenib-loaded carbon nanotubes with distinct tumour-suppressive activity in hepatocellular carcinoma. Int. J. Nanomed. 2019, 14, 8445. [CrossRef]

40. Yetilmezsoy, K.; Demirel, S.; Vanderbei, R.J. Response surface modeling of $\mathrm{Pb}$ (II) removal from aqueous solution by Pistacia vera L.: Box-Behnken experimental design. J. Hazard. Mater. 2009, 171, 551-562. [CrossRef]

41. Ahmed, M.M. Effect of different formulation factors on release characteristics of gastro-floating microspheres of ethyl cellulose/carbopol 934P encapsulating sorafenib. Int. J. Pharm. Pharm. Sci. 2019, 11, 64-70.

42. El-Shenawy, A.A.; Ahmed, M.M.; Mansour, H.F.; El Rasoul, S.A. Torsemide Fast Dissolving Tablets: Development, Optimization Using Box-Bhenken Design and Response Surface Methodology, In Vitro Characterization, and Pharmacokinetic Assessment. AAPS PharmSciTech 2017, 18, 2168-2179. [CrossRef]

43. Elsayed, M. Design and optimization of tolmetin sodium microspheres prepared by emulsification-internal gelation using response surface methodology. Al Azh. J. Pharm. Sci. 2012, 45, 383-398.

44. Motwani, S.K.; Chopra, S.; Talegaonkar, S.; Kohli, K.; Ahmad, F.J.; Khar, R.K. Chitosan-sodium alginate nanoparticles as submicroscopic reservoirs for ocular delivery: Formulation, optimisation and in vitro characterisation. Eur. J. Pharm. Biopharm. 2007, 68, 513-525. [CrossRef] 
45. Sofidiya, M.; Jimoh, F.; Aliero, A.; Afolayan, A.; Odukoya, O.; Familoni, O. Antioxidant and antibacterial properties of Lecaniodiscus cupanioides. Planta Med. 2007, 73, 212. [CrossRef]

46. Simpson, B.; Claudie, D.; Smith, N.; Wang, J.; McKinnon, R.; Semple, S. Evaluation of the anti-inflammatory properties of Dodonaea polyandra, a Kaanju traditional medicine. J. Ethnopharmacol. 2010, 132, 340-343. [CrossRef] [PubMed]

47. Díaz, M.; Rossini, C. Bioactive natural products from Sapindaceae deterrent and toxic metabolites against insects. In InsecticidesPest Engineering; Perveen, F., Ed.; InTech: Rijeka, Croatia, 2012; pp. 287-308.

48. Muthukumran, P.; Begumand, V.H.; Kalaiarasan, P. Anti-diabetic activity of Dodonaea viscosa (L) leaf extracts. Int. J. Pharm. Tech. Res. 2011, 3, 136-139.

49. Abdel-Rahman, L.H.; Abu-Dief, A.M.; El-Khatib, R.M.; Abdel-Fatah, S.M. Some new nano-sized Fe (II), Cd (II) and Zn (II) Schiff base complexes as precursor for metal oxides: Sonochemical synthesis, characterization, DNA interaction, in vitro antimicrobial and anticancer activities. Bioorganic Chem. 2016, 69, 140-152. [CrossRef]

50. Abu-Dief, A.M.; Mohamed, W. $\alpha$-Bi2O3 nanorods: Synthesis, characterization and UV-photocatalytic activity. Mat. Res. Exp. 2017, 4, 035039. [CrossRef]

51. Abdel Rahman, L.H.; Abu-Dief, A.M.; El-Khatib, R.M.; Abdel-Fatah, S.M.; Adam, A.; Ibrahim, E. Sonochemical synthesis, structural inspection and semiconductor behavior of three new nano sized Cu (II), Co (II) and Ni (II) chelates based on tri-dentate NOO imine ligand as precursors for metal oxides. Appl. Org. Chem. 2018, 32, e4174. [CrossRef]

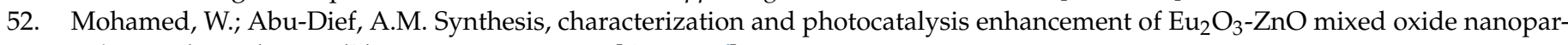
ticles. J. Phys. Chem. Solids 2018, 116, 375-385. [CrossRef]

53. Hassanien, A.; Akl, A.A.; Sáaedi, A. Synthesis, crystallography, microstructure, crystal defects, and morphology of Bi $\mathrm{Zn}_{1-\mathrm{x}} \mathrm{O}$ nanoparticles prepared by sol-gel technique. Cryst. Eng. Comm. 2018, 20, 1716-1730. [CrossRef]

54. Akl, A.A.; Mahmoud, S.A.; Al-Shomar, S.; Hassanien, A. Improving microstructural properties and minimizing crystal imperfections of nanocrystalline $\mathrm{Cu}_{2} \mathrm{O}$ thin films of different solution molarities for solar cell applications. Mater. Sci. Semicond. Process. 2018, 74, 183-192. [CrossRef]

55. Yogamalar, R.; Srinivasan, R.; Vinu, A.; Ariga, K.; Bose, A.C. X-ray peak broadening analysis in ZnO nanoparticles. Solid State Commun. 2009, 149, 1919-1923. [CrossRef]

56. Jayaseelan, C.; Rahuman, A.A.; Kirthi, A.V.; Marimuthu, S.; Santhoshkumar, T.; Bagavan, A.; Gaurav, K.; Karthik, L.; Rao, K.B. Novel microbial route to synthesize $\mathrm{ZnO}$ nanoparticles using Aeromonas hydrophila and their activity against pathogenic bacteria and fungi. Spectrochim. Acta Part A Mol. Biomol. Spectrosc. 2012, 90, 78-84. [CrossRef]

57. Sanghi, R.; Verma, P. A facile green extracellular biosynthesis of CdS nanoparticles by immobilized fungus. Chem. Eng. J. 2009, 155, 886-891. [CrossRef]

58. Masood, F.; Malik, A. Biosorption of metal ions from aqueous solution and tannery effluent by Bacillus sp. FM1. J. Environ. Sci Health Part A 2011, 46, 1667-1674. [CrossRef] [PubMed]

59. Patel, M.N.; Lakkadwala, S.; Majrad, M.S.; Injeti, E.R.; Gollmer, S.M.; Shah, Z.A.; Boddu, S.H.S.; Nesamony, J. Characterization and evaluation of 5-fluorouracil-loaded solid lipid nanoparticles prepared via a temperature-modulated solidification technique. AAPS PharmSciTech 2014, 15, 1498-1508. [CrossRef]

60. Chen, S.; Jin, L.; Chen, X. The effect and prediction of temperature on adsorption capability of coal/ $\mathrm{CH}_{4}$. Procedia Eng. 2011, 26, 126-131. [CrossRef]

61. Shi, X.L.; Dalal, N.S. Chromium (V) and hydroxyl radical formation during the glutathione reductase-catalyzed reduction of chromium (VI). Biochem. Biophys. Res. Commun. 1989, 163, 627-634. [CrossRef]

62. Collins, A.R. The comet assay for DNA damage and repair: Principles, applications, and limitations. Mol. Biotechnol. 2004, 26, 249-261. [CrossRef]

63. Alarifi, S.; Ali, D.; Alkahtani, S. Mechanistic investigation of toxicity of chromium oxide nanoparticles in murine fibrosarcoma cells. Int. J. Nanomed. 2016, 11, 1253-1259. [CrossRef]

64. Xia, T.; Kovochich, M.; Liong, M.; Zink, J.I.; Nel, A.E. Cationic polystyrene nanosphere toxicity depends on cell-specific endocytic and mitochondrial injury pathways. ACS Nano 2008, 2, 85-96. [CrossRef] [PubMed]

65. Sinha, S.; Saxena, R.; Singh, S. Chromium induced lipid peroxidation in the plants of Pistia stratiotes L.: Role of antioxidants and antioxidant enzymes. Chemosphere 2005, 58, 595-604. [CrossRef] [PubMed]

66. Rungby, J.; Ernst, E. Experimentally induced lipid peroxidation after exposure to chromium, mercury or silver: Interactions with carbon tetrachloride. Pharmacol. Toxicol. 1992, 70, 205-207. [CrossRef] [PubMed]

67. Liu, K.; Chen, P.; Lu, J.; Zhu, Y.; Xu, Y.; Liu, Y.; Liu, J. Protective Effect of Purple Tomato Anthocyanidin on Chromium(VI)-Induced Autophagy in LMH Cells by Inhibiting Endoplasmic Reticulum Stress. Biol. Trace Element Res. 2019, 194, 570-580. [CrossRef] 